\title{
Temperatura aparente de superfície nos arredores do córrego Moscados na cidade de Maringá, Paraná
}
The apparent temperature of surface in the vicinity of the stream Moscados in the city of Maringá, Paraná State, Brazil

La temperatura de la superficie aparente en las proximidades de los pequeño río Moscados en la ciudad de Maringá, estado de Paraná, Brasil

\section{Renan Valério Eduvirgem} Mestrando em Geografia, UEM, Brasil georenanvalerio@gmail.com

Maria Eugênia Moreira Costa Ferreira Professora Doutora Associada, UEM, Brasil eugeniaguart@gmail.com 


\begin{abstract}
RESUMO
As técnicas de geoprocessamento são utilizadas por diversos profissionais, principalmente por geógrafos e engenheiros. Neste trabalho será utilizado o geoprocessamento para identificação de curso d'água correlacionando com a temperatura de aparente de superfície nos arredores do córrego Moscados que está localizado na área urbana da cidade de Maringá, Paraná. A metodologia utilizada para identificação da temperatura de superfíe será utilizado o guia da o guia empregado pelo Center for Earth Observation, da Universidade de Yale, este método possui embasamento na Lei de Planck, na qual tem como propósito geral, explicar que todas as superfícies emitem energia térmica, no máximo de energia emitida por uma superfície perfeita, pode ser considerado um corpo negro. $O$ objetivo do trabalho foi tentar identificar se há possível arrefecimento da temperatura promovido pelo córrego Moscados na área urbana ao redor. Os resultados alcançados foram que não somente o córrego Moscados proporciona a mitigação da temperatura, mas a vegetação localizada entre o córrego e a área urbana, Área de Preservação Permanente (APP), possui papel fundamental no auxílio à diminuição da temperatura.
\end{abstract}

PALAVRAS-CHAVE: Geotecnologias. Temperatura aparente de superfície. Imagem de satélite.

\title{
ABSTRACT
}

The geoprocessing techniques are used by various professionals, mainly by geographers and engineers. This work will be used from the geoprocessing for identification of water course correlating with the temperature of apparent surface area on the outskirts of the stream Moscados which is located in the urban area of the city of Maringá, Paraná. The methodology used to identify the temperature of surface will be used the guide of the guide used by the Center for Earth Observation, of Yale University, this method has a foundation in the law of Planck, which has as its overall purpose, explain that all surfaces emit thermal energy, at the maximum energy emitted by a perfect surface, can be considered a black body. The objective of this study was to try to identify possible cooling of room temperature promoted by stream Moscados in the urban area around. The results were that not only the stream Moscados provides the mitigation of temperature, but the vegetation located between the creek and the urban area, Permanent Preservation Area (PPA), have a fundamental role in helping to decrease in temperature.

KEYWORDS: Geotechnologies. The apparent temperature of surface. Satellite images.

\section{RESUMEN}

Las técnicas de geoprocesamiento son utilizados por diversos profesionales, principalmente por los geógrafos e ingenieros. Este trabajo se utilizarán desde el geoprocesamiento para la identificación del curso de agua que se correlaciona con la temperatura de la superficie aparente en las afueras de los pequeño río Moscados que está situado en la zona urbana de la ciudad de Maringá, Paraná. La metodología utilizada para determinar la temperatura de superfíe se utilizará la guía de la guía utilizada por el Centro de Observación de la Tierra, de la Universidad de Yale, este método tiene un fundamento en la ley de Planck, que tiene como objetivo general, explican que todas las superficies emiten energía termal, con la máxima energía emitida por una superficie perfecta, puede ser considerado como un cuerpo negro. El objetivo de este estudio fue para intentar identificar posibles el enfriamiento de la temperatura de la habitación promovido por los pequeño río Moscados Moscados en la zona urbana. Los resultados fueron que no sólo de los pequeño río Moscados proporciona la mitigación de los efectos de la temperatura, pero la vegetación localizada entre el riachuelo y la zona urbana, Área de Preservación Permanente (PPA), tienen un papel fundamental en ayudar a la disminución de la temperatura.

PALABRAS-CLAVE: Geotechnologies. La temperatura de la superficie aparente. Imágenes satelitales. 


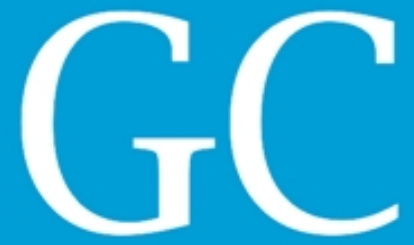

Revista Nacional de

\section{INTRODUÇÃO}

Com alusão a temática de análise de temperaturas, o primeiro estudo foi realizado na cidade de Londres pelo meteorologista Luke Howard. Gertland (2010) pauta que Luke Howard, verificou disparidade entre a temperatura da área rural comparada com a área urbana.

Já no tocante as abordagens sobre ilhas de calor têm-se, na década de 1950, nos Estados Unidos da América (EUA), os estudos do pesquisador Mitchell, tendo como maiores destaques os trabalhos intitulados: "On the causes of instrumentally observed secular temperature trends" tendo continuidade por: "The temperature of cities".

A primeira pesquisa no Brasil relacionada ao clima urbano foi desenvolvida por Carlos Augusto de Figueiredo Monteiro sendo resultante desta a tese intitulada "Teoria e clima urbano", defendida em 1975 e editada no ano seguinte. Conforme este mesmo autor em pesquisas em anos posteriores o clima urbano demonstra-se como sistema complexo, adaptativo e aberto sendo especifico para cada ambiente urbano, pois cada ambiente possui sua característica única, concomitante às alterações climáticas. (MONTEIRO, 2003).

O objetivo deste trabalho foi promover uma análise se há possível arrefecimento da temperatura aparente de superfície nos arredores do Córrego Moscados, localizado no Município de Maringá, Paraná, e também identificar as localidades com potencial de ilhas de calor e frescor (Figura 01).

Figura 01 - Localização da área de estudo: Córrego Moscado e seus arredores

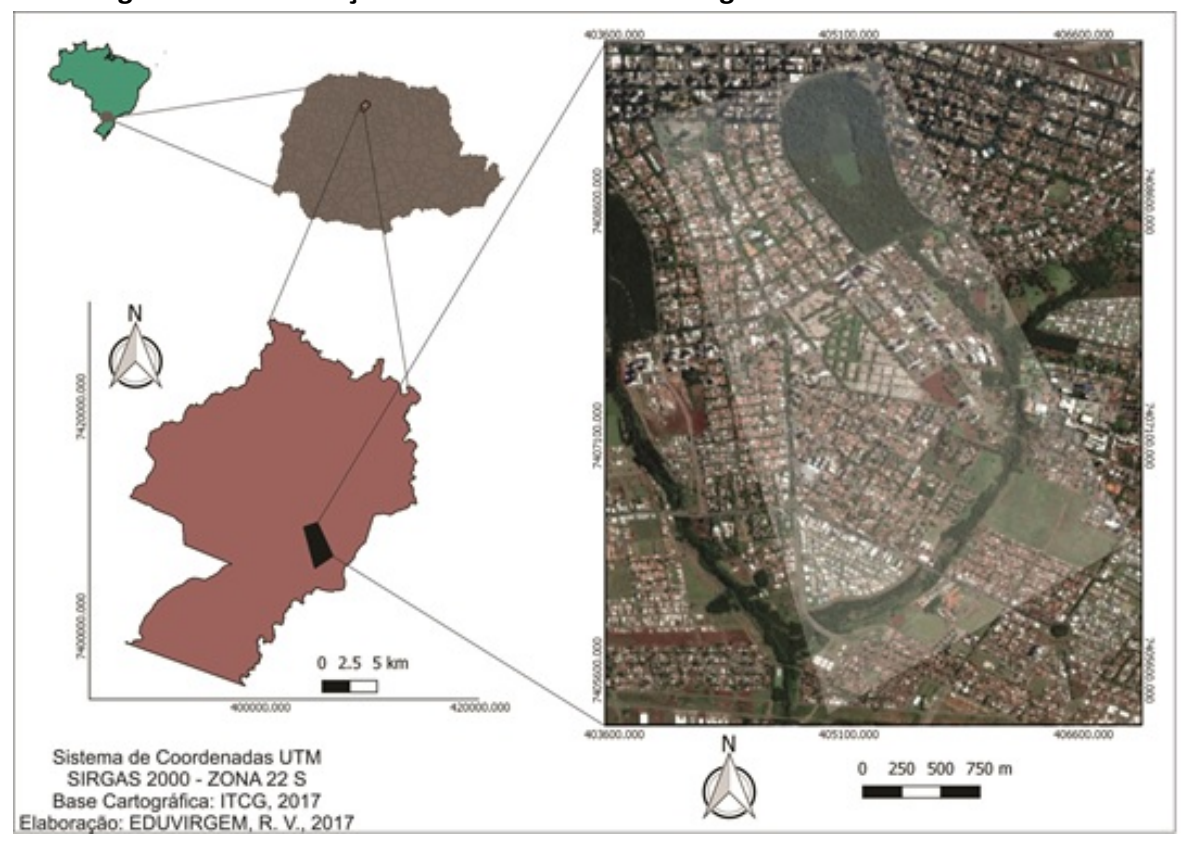

Fonte: AUTORES 
De acordo com Baggio (2014, p. 69) “o córrego Moscados está localizado na vertente sul e faz parte da bacia do rio Ivaí, tem a totalidade de sua extensão, 3.966m localizados na área urbana de Maringá e tem sua principal nascente dentro do Parque do Ingá".

\section{SENSORIAMENTO REMOTO}

De acordo com os estudos de Rosa (2005, p. 81) "Dentre as geotecnologias podemos destacar: sistemas de informação geográfica, cartografia digital, sensoriamento remoto, sistema de posicionamento global e a topografia". Dentre tantas geotecnologias, enfocamos este estudo com o sensoriamento remoto.

De acordo com Florenzano (2007), o sensoriamento remoto é uma ferramenta que permite a obter imagens através de equipamentos que captam a reflexão das radiações eletromagnéticas de objetos (alvos) localizados na superfície terrestre.

A ferramenta permite também a realização de inúmeras analises sem o pesquisador estar diretamente em contato com o local, pelo fato de que a radiação é coletada por sensores eletroópticos, deste modo ocorre à transformação em dados, as quais podem ser números, imagens e gráficos.

Na Figura 02 é demonstrado o efeito aditivo. A radiação captada pelo sensor é a radiação refletida do alvo juntamente da radiação que a atmosfera espalhou antes que atingisse a superfície do solo.

Figura 02 - 0 espalhamento atmosférico adiciona radiação na quantidade de energia refletida do alvo que chega ao sensor.

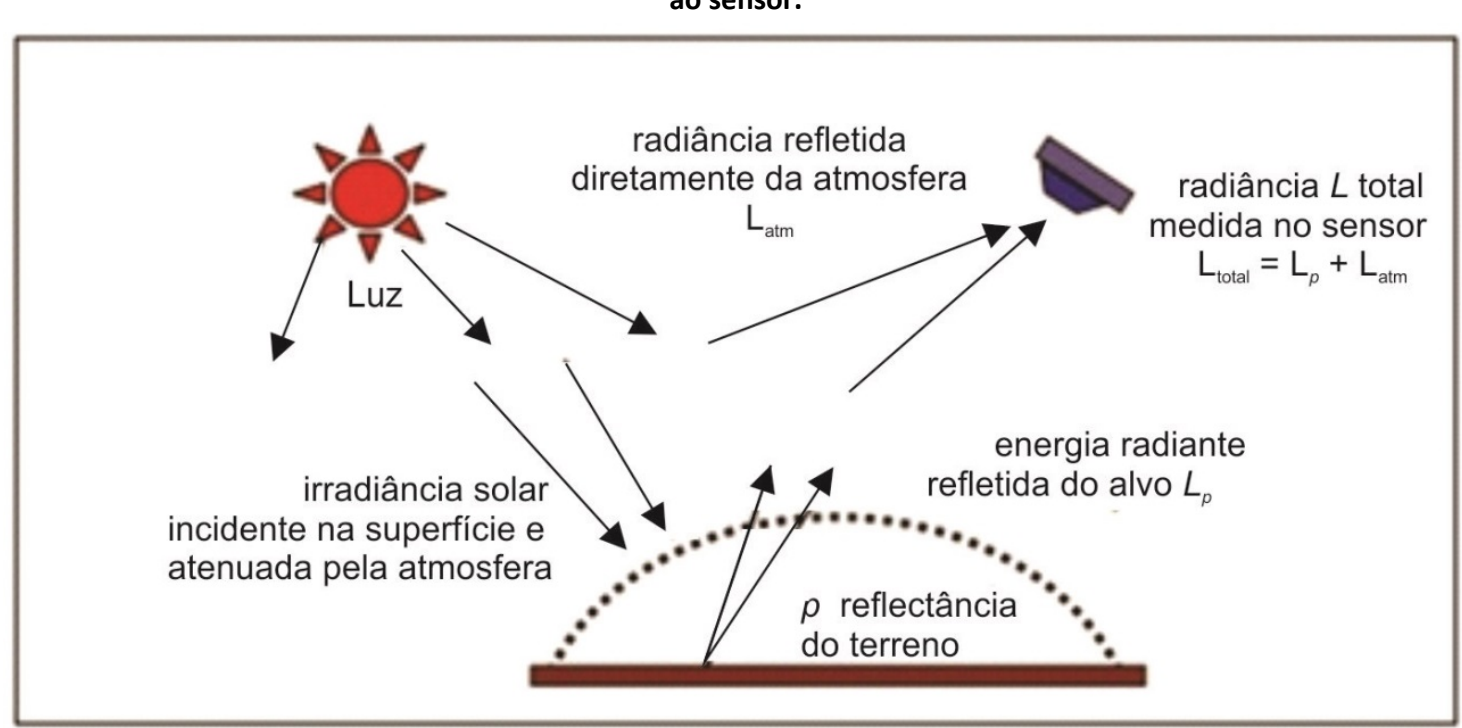

Fonte: MENESES \& ALMEIRA, 2012 
Em meados do século XIX foi tirada a primeira fotografia a bordo de um balão. Com o passar dos anos, a terminologia fotogrametria adentra o meio cientifico. Em 1873, o pesquisador Herman Vogel conseguiu capturar ondas com maiores cumprimentos, assim, iniciando o processo para as fotografias no infravermelho próximo, e este feito, inicia inúmeras contribuições ao sensoriamento remoto por meio de fotografias retiradas com pipas, pombos e aviões (GERMANO, 2012).

O sensoriamento remoto por satélites é iniciado em 1957 com o lançamento do primeiro satélite (Sputnik) pela União Soviética. Ainda em 1957 os Estados Unidos da América estavam desenvolvendo um projeto "Corona". Por meio deste projeto foram obtidas as primeiras imagens de satélite, em 1960 (GERMANO, 2012).

Em 1960, por meio de satélites tripulados, Merculy, Gemini e Apolo, foram registrados, as primeiras fotografias orbitais. Segundo Florenzano (2011) o primeiro satélite meteorológico não tripulado, da série Tiros 1, em 1960, ficou em orbita por 78 dias.

Os satélites da série Landsat são fundamentais para o sensoriamento remoto. Estes satélites Landsat surgiram originalmente com o nome ERTS-1. Segundo Florenzano (2011) em 1972, os Estados Unidos da América colocaram em orbita o primeiro satélite com recursos terrestres, que foi nomeado de ERTS-1, na qual este posteriormente foi renomeado como Landsat-1. Na atualidade existem outros satélites além do Landsat, como exemplo o satélite Francês denominado de Spot, o indiano IRS-P6, CBERS, entre outros satélites.

Quando utilizamos o sensoriamento remoto devemos ser cautelosos quanto ao albedo. Diante desta temática, Amorim (2017, p. 127) salienta que

\footnotetext{
[...] quando expostas à radiação solar, as superfícies com elevado albedo e emissividade tendem a permanecerem mais frias. Isso ocorre porque elas absorvem menos radiação e emitem mais radiação térmica para o espaço, transmitindo menos calor para seu entorno. Entretanto, quanto menor for o albedo e a emissividade maior será a absorção de calor e sua permanência no ambiente de entorno.
}

No que concerne a modelagem de ilhas de calor, Teixeira e Amorim (2017, p. 253) afirmam que a "modelagem da ilha de calor mostrou que a classe de uso da terra "urbana" tem maior influência na configuração espacial da ilha de calor, comprovando a hipótese de que as áreas urbanas densamente construídas estão relacionadas às áreas de excesso de calor".

As ilhas de calor podem inferir até mesmo na saúde humana, está evidência é contextualizada por Amorim, Dubreuil e Cardoso (2015, p. 30) com a seguinte afirmação: "[...] as ilhas de calor poderiam ser benéficas para as pessoas, entretanto, a presença de poluentes nas áreas mais quentes pode trazer agravamentos para a saúde, particularmente para os grupos humanos mais vulneráveis como os idosos e as crianças".

Deste modo, faz-se imprescindível a ascensão nos estudos em pequenas áreas com alusão as ilhas de calor, para que seja possível a identificação destes fenômenos e possíveis solução 
apropriadas para cada área, com o propósito de auxiliar na saúde humana que está atralada ao planejamento urbano.

\subsection{Satélites artificiais e aquisição de imagens}

Os satélites artificiais são empregados em diversas atividades, inclusive para a aquisição de imagens orbitais, por este fato os satélites são construídos com o propósito de captar dados por meio de sensores, realizando aquisição de dados, passando a compor então a temperatura da superfície, não precisando estar "in loco".

Para que seja possível a aquisição dos dados faz se necessário à utilização de energia solar (natural) ou produzida pelo próprio equipamento (artificial) como pode ser observado (Figura $03 \mathrm{~A}$ e B).

Os sensores passivos (Figura $3 \mathrm{~A}$ ) medem a radiação emitida ou refletida pelos alvos, oriunda de uma fonte externa, normalmente o sol. Neste contexto os sensores passivos não possuem radiação própria. Neste sensor a radiação com os alvos, de modo que, parte é refletida indo atingir o detector do sistema sensor, que esteja sobre a área irradiada. O sensor Landsat, compõe está categoria de sensores.

Os sensores ativos (Figura 3 B) possuem fonte de radiação, assim, não dependendo de um agente externo para irradiar o alvo. Deste modo, o sensor emite fluxo de radiação em uma de suas faixas espectrais, onde ocorre à interação com os alvos da superfície terrestre e a parte que é refletida é captada pelo sensor.

Figura 03 - Demonstração de sensor passivo e sensor ativo

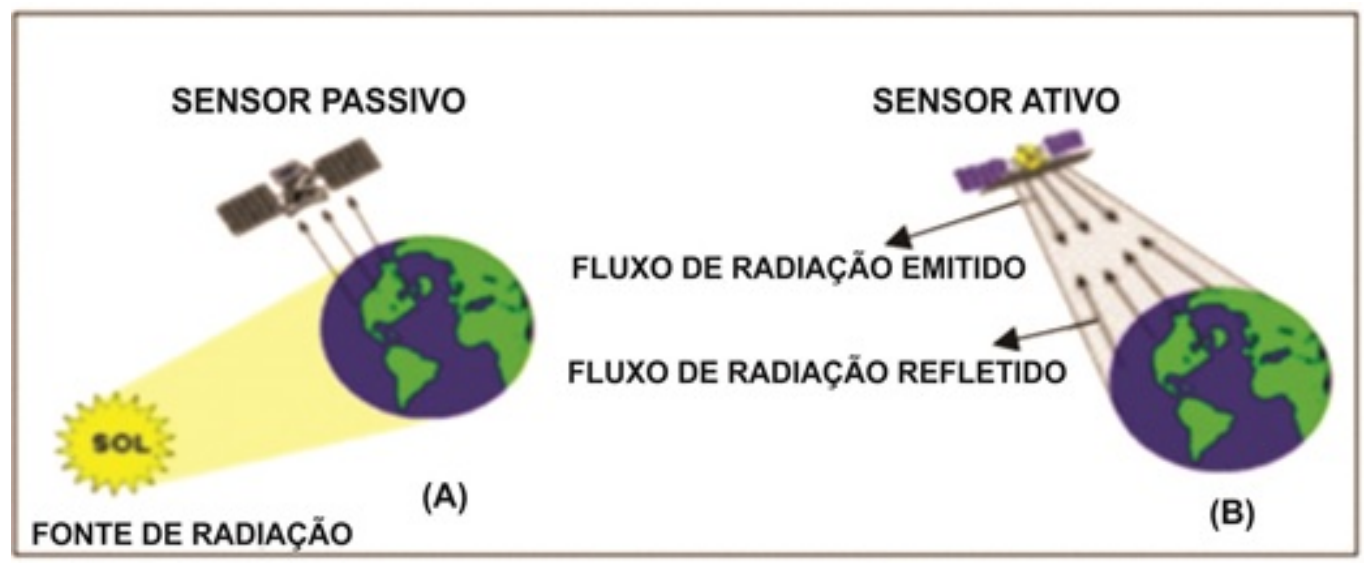

Fonte: INPE, 2001 


\section{Revista Nacional de}

\subsection{Resoluções}

Não são raras as oportunidades em que, mesmo abordando as mesmas regiões, tenhamos conflitos entre os dados. Isto acontece devido ao fato que os satélites possuem diferentes resoluções, conforme as explicações abaixo.

De acordo com Florenzano (2011) a resolução espacial é a capacidade que o sensor tem de identificar objetos em função do tamanho dos mesmos. Deste modo os satélites artificiais possuem resolução que variam de $50 \mathrm{~cm}$ a $1 \mathrm{~km}$. Assim, um sensor com resolução espacial de $20 \mathrm{~m}$, é capaz de detectar alvos maiores que $20 \mathrm{~m} \times 20 \mathrm{~m}\left(400 \mathrm{~m}^{2}\right)$.

A resolução espectral (Figura 04) é a capacidade que o sensor tem de diferenciar objetos em função da sensibilidade dos alvos, conforme suas peculiaridades. Neste contexto, Florenzano (2011) salienta que quanto mais estrita for à faixa espectral maior será a possibilidade de registrar variações de energia, no qual o alvo reflete.

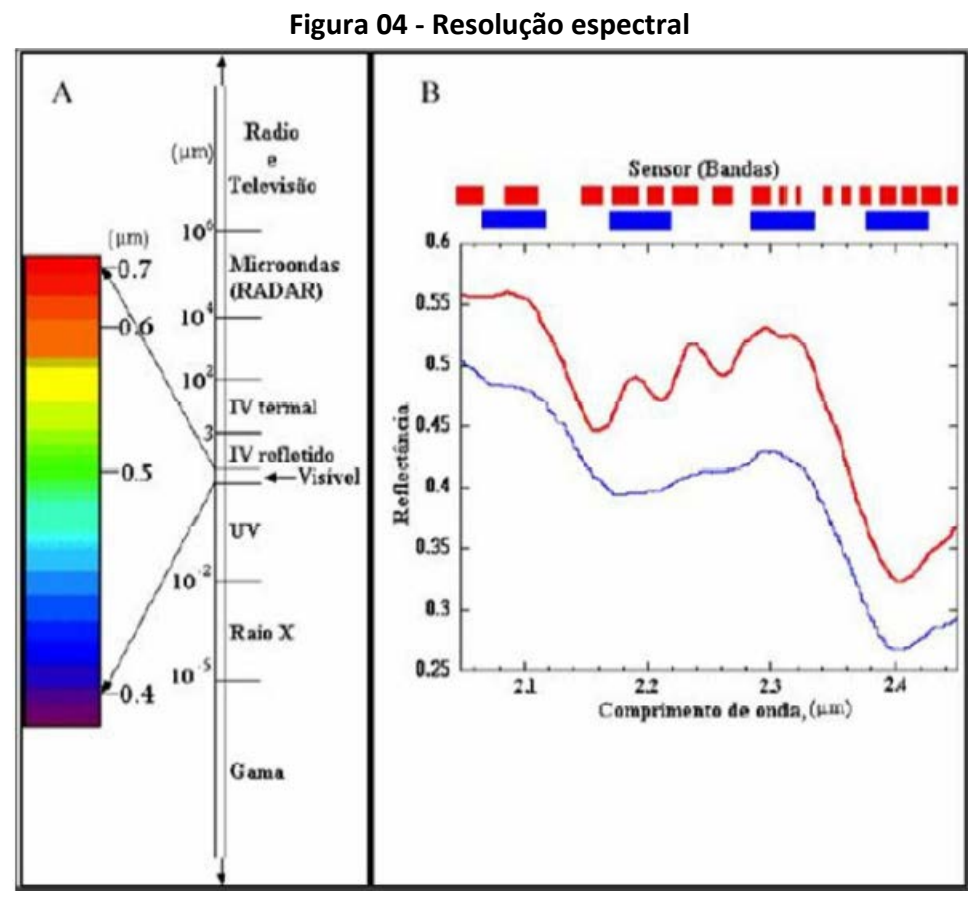

Fonte: MELO, 2002

Conforme Florenzano (2011) a resolução radiométrica determina o intervalo dos valores (associados aos níveis de cinza) que é possível utilizar para representação de imagens digitais. Deste modo, quanto maior for o nível de cinza (branco e preto), melhor será o detalhamento da imagem, como pode ser observado (Figura 05). 


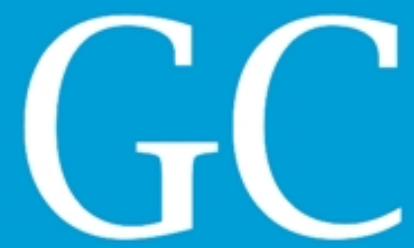

Revista Nacional de

Figura 05 - Diferença de resolução radiométrica no âmbito urbano

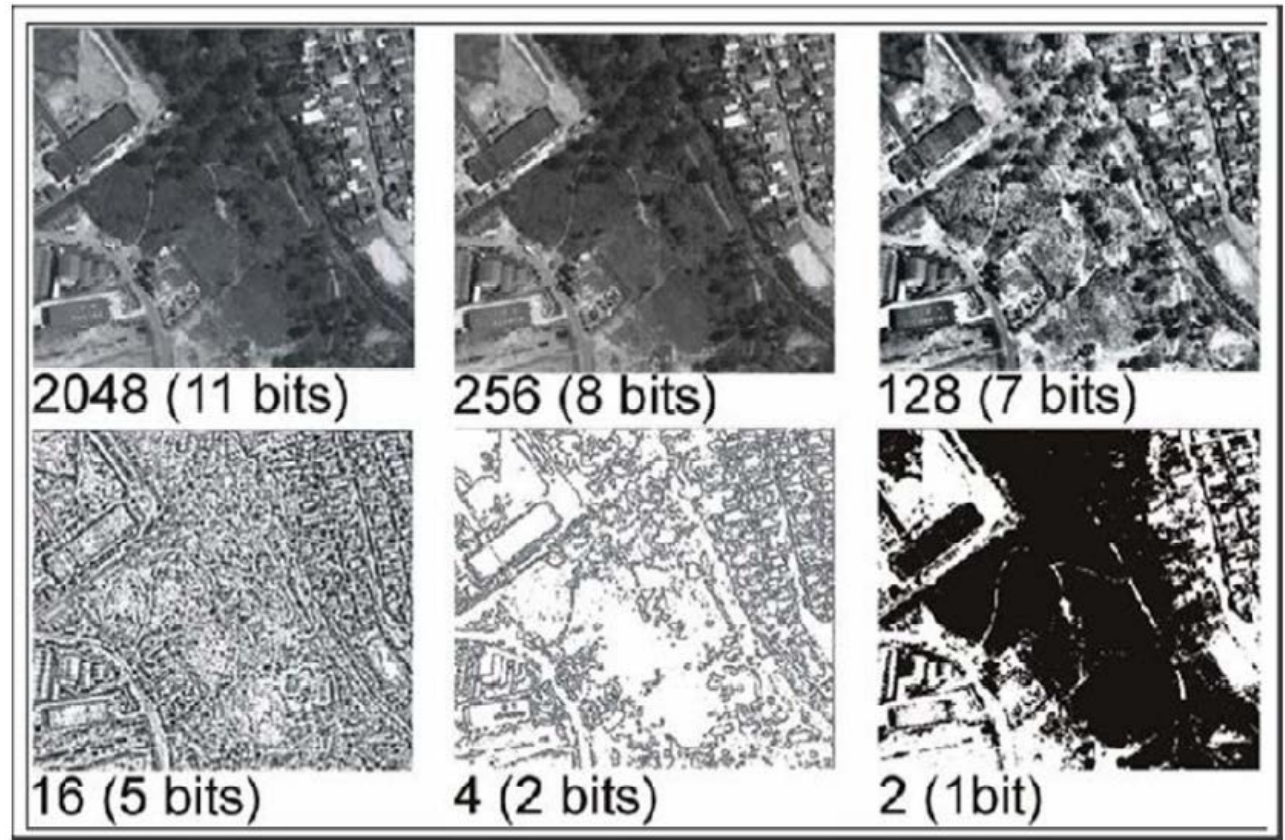

Fonte: MELO, 2002

A resolução temporal faz alusão à frequência do imageamento em uma mesma localidade ou área, isto é, quanto tempo o satélite leva para obtenção de duas imagens. O conhecimento das peculiaridades da resolução temporal de cada satélite é fundamental para os profissionais (ou mesmo o operador leigo) para a realização em estudos condizentes a eventos dinâmicos, que estes podem levar anos, meses, dias e até mesmo horas.

\section{PROCEDIMENTOS METODOLÓGICOS}

Utilizou-se para análise na área de estudo imagens de satélite Landsat 8 , na banda 10 (Infravermelho termal). As bases cartográficas foram obtidas nos sites das seguintes instituições: Instituto de Terras, Cartografia e Geologia do Paraná (ITCG).

A área delimitada neste estudo foi escolhida levando em consideração as características morfológicas (expansão urbana e vegetação), podendo deste modo identificar e representar os locais que apresentam temperaturas aparente de superfícies mais elevadas.

A metodologia utilizada foi iniciada pela leitura de livros, revistas cientificas, bem como trabalhos publicados em anais de congressos, de maneira a embasar o direcionamento das técnicas as quais serão aplicadas neste estudo, propiciando deste modo embasamento com alusão ao panorama geral referente a temperatura aparente de superfície.

Para atender os objetivos aplicados da pesquisa, foram adquiridas imagens da área de estudo no sítio da United States Geological Survey (USGS). 
Para obter os valores de temperatura de superfície foi utilizado o software Quantum Gis, software gratuito. Os dados de entrada foram as imagens do satélite Landsat 8 na banda 10 (infravermelho termal), em seguida realizou-se o processamento das imagens, de modo que cômputo da radiância espectral de cada banda, onde ocorre a efetivação da calibração radiométrica, em que o número digital (ND) de cada pixel da imagem é convertido em radiância espectral monocromática. Na banda 10, denominada termal, na qual a faixa espectral encontrase entre 10,60-11,19 $\mu \mathrm{m}$, a radiância representa a energia emitida por cada pixel. Em seguida os valores de radiância são convertidos à reflectância aparente, e desta maneira, foi possível a aquisição dos valores de temperatura.

Na determinação da temperatura de superfície foi utilizado o guia empregado pelo Center for Earth Observation, da Universidade de Yale, este método possui embasamento na Lei de Planck. A Lei de Planck tem como propósito geral, explicar que todas as superfícies emitem energia térmica, no máximo de energia que é possível ser emitido por uma superfície perfeita, pode ser considerado um corpo negro. Trata-se de um corpo hipotético que pode absorver e emitir a radiação eletromagnética em todos os comprimentos de onda de forma isotrópica, que pode ser produzida como a quarta potência da temperatura de superfície do objeto (Equação 1).

Energia emitida por um corpo negro $=6 \mathrm{~T} 4$

Onde " 6 " constante de Stefan-Boltzmann (5,67 x 10-8 W/m2 k4).

Todavia, nenhuma superfície real comporta-se como um corpo negro, deve-se considerar a seguinte fórmula (Equação 2):

Energia real emitida $=\varepsilon 6 \mathrm{~T} 4$

Onde " $\varepsilon$ ": emissividade da superfície, que varia entre 0 e 1 .

Os elementos presentes na terra apresentam emissões que variam de 0,8 a 0,95 . Sendo alguns materiais como metais, sem revestimento, podem apresentar valores variando de 0,2 a 0,6.

Para ser possível a obtenção dos valores de temperatura da superfície, foi utilizado o tutorial da Universidade de Yale, que apresenta duas formulas, sendo a primeira responsável pela transformação dos valores ND (números digitais coletados via satélite), que vão de 0 (branco) a 255 (preto), em valores de radiância (Equação 3).

CVR1 = gain $. N D+$ bias

Onde: 
CVR1 => Valor de radiância do pixel

gain => Coeficiente de calibração termal (0.05518)

ND => Número Digital (0 a 255)

Bias $=>$ Coeficiente de calibração (1.2378)

Os valores de bias e gain são oriundos da calibração dos sensores, que interferem diretamente nos dados de temperatura. Ao final do lançamento dos dados ND para radiância, aplicou-se a fórmula (Equação 04) para transformação dos valores em temperatura, cujos resultados foram expressos em graus Celsius.

$$
T=\frac{K_{2}}{\operatorname{In}\left(\frac{K 1 X \varepsilon}{C V_{R_{1}}}\right)+1}-273,15
$$

Onde:

$\mathrm{T}=>$ Temperatura em Kelvin

CVR1 => Valor de radiância dos pixels da imagem anterior

$\varepsilon=>$ Emissividade (foi adotado o valor de 0.95)

K1 $607.76=>$ Constante de calibração

K2 1260.56 => Constante de calibração

\section{RESULTADOS E DISCUSSÕES}

Para averiguação da temperatura aparente de superfície utilizamos 03 imagens do Satélite Landsat 8, órbita 222, do mês de maio, na seguinte cronologia: 2015, 2016 e 2017, sendo classificadas as temperaturas em muito baixa, baixa, média e alta. As condições atmosféricas das imagens foram corrigidas. (Figura 06). 


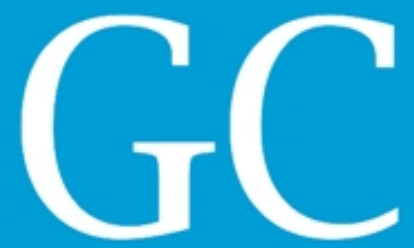

Revista Nacional de
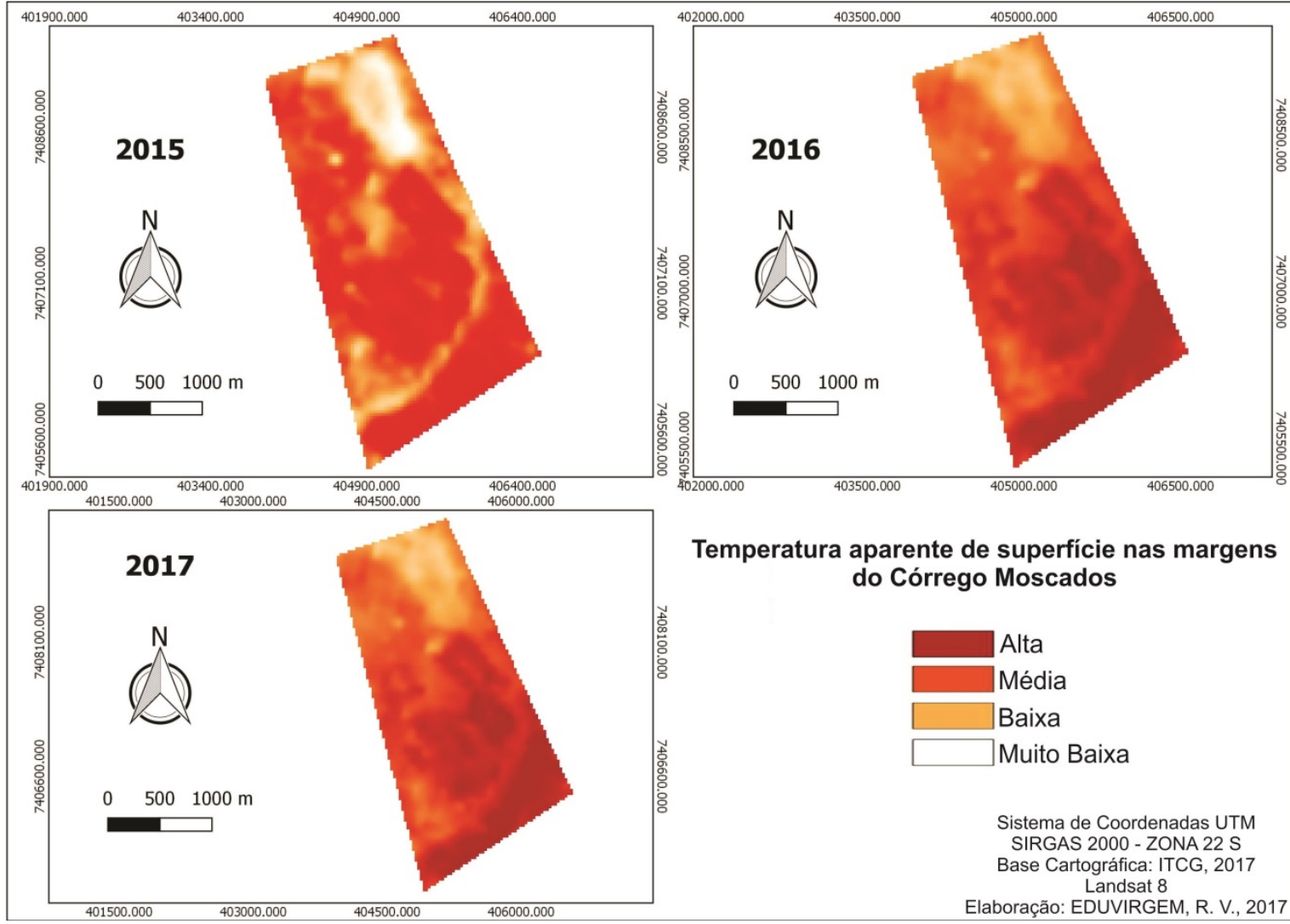

Temperatura aparente de superfície nas margens do Córrego Moscados

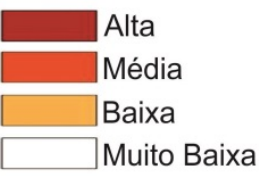

Sistema de Coordenadas UTM SIRGAS 2000 - ZONA 22 S Base Cartográfica: ITCG, 2017

Fonte: AUTORES

Com os resultados conseguimos observar que em maio de 2015 as temperaturas foram mais amenas na série estuda. Nas proximidades do córrego Moscados a temperatura é menor. A temperatura começa a ascender conforme aumenta-se a distância do curso d'água. A noroeste da imagem termal localiza-se um local com temperaturas classificada como muito baixa, nesta localizadade encontra-se o Parque do Ingá, onde localiza-se a nascente do Córrego Moscados. A água é represada para manter um lago dentro deste Parque, contribuindo diretamente para o arrefecimento das temperaturas.

No mês de maio de 2016 as temperaturas aparentes de superfícies foram muito superiores a 2015, de modo que até mesmo o Parque do Ingá obteve temperatura superior ao ano antecessor.

Em maio de 2017 as temperaturas prevaleceram na categoria alta, entretanto as temperaturas aparentes de superfícies foram inferiores a maio de 2016, porém superiores a maio de 2015 . Em maio de 2017 foi nítida a eficácia no que tange ao arrefecimento não somente por meio do córrego Moscados, mas também de sua nascente com água represada no interior do Parque do Ingá. 
Ao sul do córrego Moscados as árvores são de porte inferior em relação às árvores ao norte do Córrego, de modo que a evidência é nítida ao norte da imagem termal com temperaturas de superfícies inferiores ao norte da área de estudo.

Diante do exposto, as áreas mais quentes são os prováveis pontos de ihas de calor, sendo o corrégo Moscados, um importante mecanismo de arrefecimento da temperatura em microescala concomitante ao Parque do Ingá funcionando com ilhas de frescor.

\section{CONCLUSÃO}

Com a cronologia analisada foi possível verificar que o córrego Moscados auxilia no arrefecimento das temperaturas ao seu redor. O Parque do Ingá apresentou-se com importante participação na amenização, uma vez que a nascente do córrego Moscados está represada em meio à vegetação, sendo este conjunto uma ilha de frescor. As partes mais quentes prováveis ilhas de calor.

Aconselha-se nas áreas mais quentes que seja plantado árvores da floresta estacional semidecidual, na qual compõem as espécies nativas da região. Assim, sugerimos as seguintes espécies da Família Bignoniaceae: Handroanthus ochraceus (Cham.) Mattos, Jacaranda micranta Charm., Zeyheria tuberculosa (Vell.) Bureau ex Verl.; Da Família Boraginaceae: Cordia americana (L.) Gottschling \& J. S. Mill., Cordia ecalyculata Vell., Cordia sellowiana Cham., Cordia superba Charm., Cordia trichotoma (Vell) Arráb. ex Steud.; Da Família Fabaceae: Albizia niopoides (Spruce ex Benth.) Burkart, Cassia ferrugínea (Schrad.) Schrad. ex DC., Ormosia arbórea (Vell.) Harms.

Sugerimos estas espécies, pois elas apresentam elevadas altitudes em seu estágio avançado de desenvolvimento. Estas árvores auxiliaram na mitigação das temperaturas aparentes de superfície, assim, diminuindo as possíveis ilhas de calor locais, também inferindo de maneira direta na saúde humana, com uma medida simples no planejamento urbano por parte da gestão municipal, optando pela utilização de árvores de grande porte.

\section{AGRADECIMENTOS}

Agradecimentos à Fundação CAPES, pela concessão da bolsa de nível de mestrado que permitiu a realização deste estudo.

\section{REFERÊNCIAS}

AMORIM, Margarete Cristiane de Costa Trindade. Detecção remota de ilhas de calor Superficiais: exemplos de cidades de porte médio e pequeno do ambiente tropical, Brasil. Finisterra, v. 52, p. 111133, 2017.

AMORIM, Margarete Cristiane de Costa Trindade; DUBREUIL, Vincent; CARDOSO, Renata dos Santos. Modelagem espacial da ilha de calor urbana em Presidente Prudente (SP) Brasil. Revista Brasileira de Climatologia, v. 16, p. 29-45, 2015. 


\section{Revista Nacional de}

BAGGIO, Jefferson Merlin. A influência da tecnogênese sobre os canais fluviais da área urbana de Maringá - PR. 2014. 95 f. Dissertação (Mestrado em Geografia), Programa de Pós-Graduação em Geografia. Universidade Estadual de Maringá, Maringá, Paraná, 2014.

FLORENZANO, Teresa Gallotti. Iniciação em sensoriamento remoto. São Paulo: Oficina de textos, 2007.

FLORENZANO, Teresa Gallotti. Iniciação em sensoriamento remoto. São Paulo: Oficina de textos, 2011.

GARTLAND, Lisa. Ilhas de Calor: como mitigar zonas de calor em áreas urbanas. Tradução: Silvia Helena Gonçalves. São Paulo: Oficina de Textos 2010.

GERMANO, Paulo José Moraes Monteiro e Teixeira. Investigação Multitemporal de Ilhas de Calor e de Frescor em Maringá, Paraná, Utilizando Imagens do Satélite Landsat - 2000 a 2010, 2012. Dissertação (Mestrado) Universidade Estadual de Maringá.

INPE. Instituto Nacional de Pesquisas Espaciais. 50 Anos do INPE. 2011 a. Disponível em: $<$ http://www.inpe.br/50anos/apresentacao.php?tipo=1>. Acesso dia 07/08/2016.

MENESES, Paulo Roberto; ALMEIDA, Tati de (Org.). Introdução ao Processamento de imagens de sensoriamento remoto. Brasília: UNB/CNPq, 2012. 266 p. Disponível em: <http://www.cnpq.br/documents/10157/56b578c4-0fd54b9f-b82a-e9693e4f69d8> Acessado em: 28/04/2017.

MELO, Danilo Heitor Caíres Tinoco Bisneto. Uso de dados Ikonos II na análise urbana: testes operacionais na zona leste de São Paulo. São José dos Campos: INPE, 2002. 146p. Disponível em: <http://mtcm12.sid.inpe.br/col/Sid.inpe.br/marciana/2003/04.14/doc/publicação.pdf>. Acesso em: 09/12/2016.

MONTEIRO, Carlos Augusto de Figueiredo. Clima Urbano. São Paulo: Editora Contexto, 2003.

ROSA, Roberto. Geotecnologias na geografia aplicada. Revista do Departamento de Geografia, v. 16, p. 81-90, 2005.

TEIXEIRA, Danielle Cardozo Frasca; AMORIM, Margarete Cristiane de Costa Trindade . Ilhas de calor: representações espaciais de cidades de pequeno porte por meio de modelagem. GEOUSP (USP), v. 21, p. 239-256, 2017.

USGS - United States Geological Survey. Catalogo de imagens. Disponível em: <https://earthexplorer.usgs.gov/>. Acesso em: 15 fev. 2017.

YALE UNIVERSITY. EARTH OBSERVATORY - Converting Landsat TM and ETM + thermal bands to temperature. 2008. Disponivel em <http://www.yale.edu/ceo/> Acesso em 22/08/2016. 